\title{
CORRECTIONS
}

\section{Author Correction: Imaging tau and amyloid- $\beta$ proteinopathies in Alzheimer disease and other conditions}

Victor L. Villemagne, Vincent Doré, Samantha C. Burnham, Colin L. Masters and Christopher C. Rowe

Nature Reviews Neurology (2018) https://doi.org/10.1038/nrneurol.2018.9

Published online 16 February 2018

In Figure 1 of this article as originally published, the chemical structure at bottom right was incorrectly labelled ${ }^{18} \mathrm{~F}-\mathrm{PM}$-PBB3. The text label has been corrected to ${ }^{18} \mathrm{~F}-\mathrm{PBB} 3$ in the PDF and HTML versions of the article. As of this date, the structure of PM-PBB3 (also known as APN-1607) has not yet been published.

https://doi.org/10.1038/s41582-018-0021-z I Published online 7 June 2018

\section{Original}

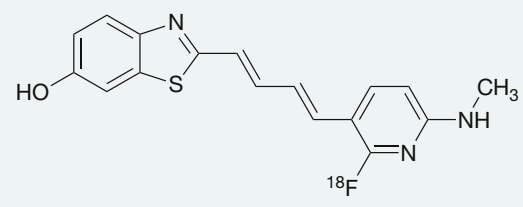

${ }^{18}$ F-PM-PBB3

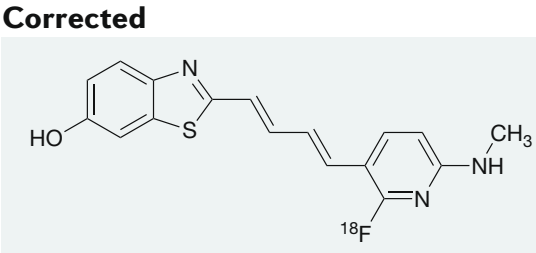

${ }^{18}$ F-PBB3 